\title{
Alastair Sloan: 'Dentists have already been practising regenerative medicine for about 80 years'
}

Please send any ideas for feature articles for consideration to:

Ruth Doherty,

Managing Editor,

British Dental Journal,

The Macmillan Building,

4-6 Crinan Street,

London,

N1 9XW

Email: r.doherty@nature.com

Alastair Sloan, speaker at the 2012 BDA Christmas Lecture, describes a regenerative future for dentistry, the standing of UK dental research and his scientific heroes

\section{Why were you attracted to studying teeth?}

When I was looking for a PhD project back in 1993, the University of Birmingham School of Dentistry had one available which sounded very appealing. It was about the development of a 3D model system for growing teeth. So studying teeth was a bit more serendipity than anything else. In the course of my $\mathrm{PhD}$, I found skeletal tissues, especially the hard tissues like dental tissues and bone, captivating. Their biology is unique. Skeletal tissue is fundamental in terms of its role in the body with quite well-defined repair processes which are quite different to other aspects of repair in the body. I found it a fascinating tissue to be involved in.

From a regenerative point of view, tissue strategies were becoming more and more interesting back in the late 1990s when I got my $\mathrm{PhD}$. Engineering bones, fracture repairs or repairing dental tissues to maintain functionality of teeth became more appealing. So I made a decision once I got my $\mathrm{PhD}$ that I was quite keen to stay in the field of general mineralised tissue.

\section{Who or what inspired you to become a stem cell scientist?}

Aged 18, doing my A-levels, I really couldn't decide what to do with my life with the exception that I would have loved to play saxophone in a jazz band! (That wasn't viable at the time.

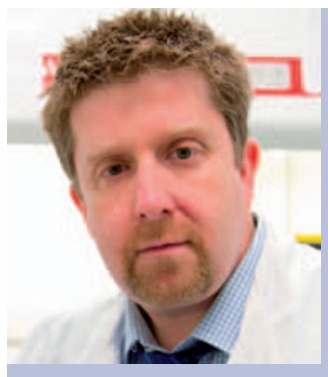

Professor Alastair Sloan is Head of Tissue Engineering \& Reparative Dentistry at Cardiff University's School of Dentistry. He took up the position and established his Mineralised Tissue Group at Cardiff in 2005 when he moved there from the University of Birmingham. Alastair's research interests are in the field of mineralised tissue regeneration, focusing on dentine and bone and the translation of the understanding of these processes to novel clinica treatments. Specifically, his research is focused on understanding the role of stem/progenitor cells in mineralised tissue regeneration and dentine/pulp physiology in relation to disease and treatment. He now leads a department of over 60 academic staff, technicians, postdoctoral researchers and postgraduate students. Alastair is the past-president of the Pulp Biology and Regeneration Research Group of the International Association for Dental Research (IADR). In 2011 he was awarded the IADR Distinguished Scientist Young Investigator Award for his research to date.

Though I do play a lot now and have a great second career as a musician.) My father was a scientist so I watched TV science programmes, such as Tomorrow's World and QED with him. I became a bit of a science geek but I sort of balanced that out by being a musician too. As I wasn't sure what I wanted to do in the future, I chose a broad degree in biology and biochemistry and it turned out that I found cell biology to be quite fascinating.

During my PhD I became interested in clinically-focused work. I wanted my research to have a particular end-point in which someone physically benefited. I suppose the idea that I wanted my research to end up in a patient meant that I was always going to have a career in translational research.

\section{What are you working on now?}

My group's research involves three key areas all interlinked around the area of mineralised tissue regeneration. One particular area is looking at the potential functionality of adult stem cells from the dental pulp and bone marrow. We look at their functions in situ to understand their cell biology and how they can be harvested. We are trying to find out how to control the repair processes that occur naturally in teeth so that we may be able to direct these processes through normal clinical therapies.

Dental pulp stem cells (DPSCs) are easily accessible: if you just extract a tooth you can collect and isolate a population of these cells. In our group we are looking at the biology and the potential of these cells to make a very clear definite answer as to whether or not they can be used for tissue engineering and repair.

Our group is also looking at developing novel biological filling and restorative materials. So rather than using current composite materials which are 
relatively inert, we look to see if we can modify existing clinical treatments and develop new bioactive restorations and restorative materials that can drive a repair response. For example, we are investigating whether we can modify composite materials to harness stem cell behaviour to drive tissue repair at the base of a cavity; so not only would the dentist plug the gap with the composite as currently happens, but the restorative material would drive a certain amount of repair in the cavity as well, which would hopefully increase the longevity of the restoration. That would to a certain extent make fillings more bioactive than the reasonably inert materials that we have at the moment.

The third area that our group is heavily involved in is controlling infection - eg understanding how opportunistic pathogens infect the pulp to drive pulpitis but also developing novel delivery vehicles to transport antimicrobials to infected pulps or to very deep lesions. We are developing materials for restorations and for endodontic practice which are antimicrobial or biocidal in nature rather than being relatively inert as they are at the moment. We think that could have great potential in the future for removing infection more effectively than we currently can.

All our work is about changing current practice by developing materials rather than trying to be far too extravagant and making brand new therapies. I think we can make headway by just tweaking and changing current clinical practice.

\section{You mention that dental pulp stem cells might be different to other types of stem cells - in what way?}

We have looked at their growth characteristics and there are some key differences, for example in their proliferation rates and ability to differentiate into different lineages. Their resistance to aspects of inflammation and oxidative stress is different. Some key aspects of their biology make them different to bone marrow stromal cells (BMSCs) in a good way. The more we learn about them the more they do seem to be a very useful cell source.

\section{What is the future for stem cells in dentistry - where will it be in ten years time?}

About ten years ago I was asked the very same question by BBC West Midlands and I said within ten years we will be at position ' $\mathrm{X}$ ' and we are nowhere near it!

I think the idea of using stem cell therapies for repairing teeth will be realised, probably in about 15-20 years time, but I don't think it will involve injecting the cells into patients. Our own work is involved in actually harnessing the functionality of the cells in the patient rather than taking the cells out to do something with them and putting them back in. We look at whether we can develop materials or strategies that control the stem cell behaviour in situ in the patients' pulpal tissue to drive a repair response. That's where I think there may be a realisation of a clinical therapy sooner rather than later.

We are looking to modify current clinical practice by developing new materials which would drive repair at the base of a cavity. We would be harnessing stem cell biology by doing that. All you are doing is controlling or mediating the natural repair response to your own end. Orthopaedic surgeons have done that in terms of bone fractures for many years and I think that we can start doing that in dentistry now. By driving repair at the base of a filling and generating reparative dentine which is atubular (so bacteria can't easily migrate down it), you can extend the residual dentine thickness at the base of a cavity avoiding shrinkage, the risk of micro-leakage and re-infection. You could possibly even put fillings in deeper cavities because you can drive some repair at the base of them.

I don't think growing teeth is the future, although it certainly is feasible. However, given that patients want to come to the dentist, get treated and go again reasonably quickly, I don't think that trying to grow teeth over a long period of time is clinically feasible. Though it is a nice idea and certainly can be done and Paul Sharpe's lab have shown the biology of this beautifully.

Other ways of harnessing stem cells might be to generate hard tissue in a root canal; so you actually fill the pulpal chamber with hard tissue rather than putting something like gutta percha down there, or you could do a mix of both. All you are doing is using the natural repair process to repair the tooth in the patient's mouth.

If you did want to actually use the cells for tissue engineering, the other aspect which might work could be engineering pulps. My own group is doing some work on this. The question being: if you have a partial pulpitis can you put some stem cells, or some material that has been generated from the patient's cells, back into the pulpal chamber to integrate with the partial pulp that's left? That may well be feasible and it would effectively change the face of endodontic treatment. I think vital pulp therapy is where we will see the greatest potential of regenerative medicine within dentistry.

\section{Storage of dental pulp stem cells has met with recent controversy in the UK - what is your view on this?}

There is not currently enough evidence there to say whether or not this is worth doing. The more we play about with these cells the more we see they are very different to BMSCs and other mesenchymal stem cells. They are unique and no doubt there is potential there. However, until we know more about their potentiality and biology, banking them on the basis that they might be useful doesn't really sit comfortably with me. In the future there may be a very good need to do that and patient cell therapies, where you use a patient's own cells to drive a repair process, may well prove very useful. I think we need to learn more about these cells and be more realistic when talking to patients about this process.

\section{What are the challenges and/or limitations facing stem cell research?}

The obvious one is funding - there is a lot of high quality stem cell research going on and there isn't enough funding to go around. In my capacity as a funding application reviewer and as an applicant myself, I see a significant number of high quality applications that don't get funded. That's just the nature of the beast at the moment.

Another limitation is that we do not yet understand fully what stem cells can 
and can't do. The media could help by not being quite so excitable and a bit more pragmatic when data come out.

Like every other lab, we isolate stem cells from tissues, grow them and characterise them by what we think are the right markers. There is a body of thought now that says maybe they are not right. We mark the cells as stem cells because they have a high proliferative capacity - they can grow and grow. However, if you look at stem cells in the body they do not grow and grow. So we still need to do a lot more basic research to understand the biology and the functionality of these cells before we can get too far ahead of ourselves and use them for trials.

Yes, some trials have been very good, for example Anthony Hollander's chondrocyte work with the trachea of a patient. However, he would be the first to admit that the actual tissue engineering side of that wasn't perfect. But it didn't need to be because it worked and the patient's life was saved. Maybe we want to try and be too perfect and we, as a community, need to be a bit more pragmatic about the research that we are doing.

However, ultimately funding is the issue.

\section{In your career to date, what are you most proud of?}

I am very proud of the IADR Young Investigator Award which I was awarded at the 89th IADR general session in San Diego in March 2011. This IADR award is one of the 16 IADR Distinguished Scientist Awards, one of the highest honours bestowed by IADR. I was immensely proud of being nominated for and receiving that award. It was a great reflection of the quality of mentors I've had both at Birmingham and here at Cardiff and of the quality work that my research group has done. I am immensely proud of that achievement; both for my group and the school in Cardiff more than anything else.

\section{What is your view on the strength of dental research in the UK?}

There is some excellent dental research in the UK - high quality research from both the biological, applied clinical sciences and social sciences areas. I have seen it improve immeasurably since I came into the field in 1993. UK dental research now holds its own with our colleagues in North America and Europe, despite the fact that we don't have a dedicated funding source as they have in the US (ie the National Institute of Dental and Craniofacial Research [NIDCR]).

We still have a lot to learn. No one is under the illusion that we are at the top of the tree yet, though we are getting better year on year. The British Society for Oral and Dental Research (BSODR) and dental schools are driving up the quality of dental research. This is helped by the quality of cross-school and cross-faculty collaborations. I chair the research committee for the Cardiff Institute for Tissue Regeneration and Repair (CITER), which has been established for ten years. That network has meant I have been able to collaborate with more mainstream medical, pharma and biosciences researchers to the point that I now have clear collaborators in the schools of medicine and pharmacy. My research actually looks outside of dentistry and the application of some of the work we are doing sits outside of dental research, which has helped to improve some of the quality of the work that we do here in Cardiff. I know similar networks also exist in other dental schools driving up the quality of the research. It's good, it's getting better, but I think we can get better still in the UK.

\section{How should dentists interested in learning more about stem cell research go about it?}

They should talk to their basic science colleagues in dental schools. They should go along to some of the BSODR and IADR meetings and attend biology talks. Organisations like the BDA should invite more scientists from the field to give understandable talks to more clinicallybased colleagues.

\section{What scientific discovery do you wish you could have been responsible for?}

I suppose the one that made a massive breakthrough in cell biology was Watson and Crick's discovery of the structure of DNA. This was so groundbreaking and opened the doors to so much understanding of biology; if you could do something like that it would be fairly special.

Cardiff's own Sir Martin Evan's more recent work on embryonic stem cells and gene knockout has also been amazing; as has the current Nobel Prize for Medicine winner Shinya Yamanaka for his work on induced pluripotent stem cell work (iPS cells). These are all key discoveries that break new ground in stem cell research.

\section{Five points about dental pulp stem cells (DPSCs) that dentists should know?}

1. DPSCs are more than likely responsible for the formation of a dentine bridge in a pulpal exposure

2. DPSCs are probably not one single type of progenitor cell; one or two possible niches may exist in the pulp

3. DPSCs can be used therapeutically if we can control their behaviour in situ

4. DPSCs may represent a very powerful stem cell source for other aspects of tissue engineering, which means dentists may become heavily involved in regenerative medicine

5. Dentists have already been practising regenerative medicine for about 80 years and it's only in the last 25 years that we have been working out the biological evidence for this. In fact, calcium hydroxide causes a dentine bridge formation and does so by releasing growth factors from surrounding dentine that differentiates dental pulp stem cells into new odontoblasts that makes dentine.

\section{What would your dream discovery be?}

I've been working on the regeneration of the dentine-pulp complex since I started my $\mathrm{PhD}$ in 1993. So if, before I retire, I can translate either our regenerative materials or our antimicrobial materials from the bench to the clinic I will be a very happy scientist. That would be a good end to a lifetime's research.

Interview by Ruth Doherty, $B D J$

Alastair will be giving a Christmas Lecture at the BDA on Thursday the 13th December. His talk, entitled 'Regenerative dentistry and stem cells: current thoughts and research', will subsequently be made available to all BDA members to view online. More information at www.bda.org/xmaslecture. 